\title{
Interdisciplinary Approach to Address the Dynamics of Water Distribution Systems for Engineering Student Education
}

\section{Prof. Youngwoo Seo, University of Toledo}

Dr. Youngwoo (Young) Seo is an assistant professor in the Department of Civil Engineering at the University of Toledo. He is also jointly appointed to the Department of Chemical \& Environmental Engineering. He received my Ph.D. (2008) in environmental engineering at the University of Cincinnati. His research interests include the molecular scale analysis of bacteria adhesion and biofilm formation in water and wastewater systems. Also, he has been working with environmental sensors and sustainable bioremediation processes. Since joining the University of Toledo in 2008, he have been teaching water resources engineering as well as water supply $\&$ treatment courses for both graduate and undergraduate students.

\section{Ms. Kimberly Mary Coburn, University of Toledo}

Ms. Kimberly Coburn has recently completed her Master's Degree in Civil Engineering at the University of Toledo. She graduated Summa Cum Laude from the University of Toledo in the Summer of 2011 with a Bachelor's Degree in Civil Engineering and a Minor in Astrophysics. Her academic career contains numerous awards for scholastic achievement, research, and teaching.

While completing her undergraduate, Ms. Coburn completed co-ops or internships with the City of Toledo, Detroit Edison, and Poggemeyer Design Group. Currently, she is working with Dr. Youngwoo Seo at the University of Toledo studying the inactivation of bacteria in water distributions systems. She has participated in several studies and manuscript preparations regarding the analysis of bacteria through the operation of annular reactors, microbial flow cells, and batch experiments. Ms. Coburn has also worked on projects for monitoring water quality using both analytical and computational techniques.

\section{Dr. Donald V. Chase, University of Dayton}




\title{
Interdisciplinary Approach to Address the Dynamics of Water Distribution Systems for Engineering Student Education
}

\begin{abstract}
Water distribution systems have complex environments, where biological and chemical reactions occur during the hydraulic conveyance of water. However, there have not been any comprehensive and systematic approaches to educate undergraduate students toward understanding this complex system. Significant integration of chemical, biological and hydraulic dynamics are required to understand, upgrade and design water distribution systems.

In spite of the complexities in water distribution systems and increased public health risks due to aged water distribution systems, the hydraulic courses that are currently taught to engineering students (civil, chemical, and environmental engineering students) only focus on the physical dynamics of fluids. Furthermore, there is also a lack of commercially available educational materials that address both the theory and application of integrated water distribution system dynamics. In that sense, there are significant needs for engineering students to understand physical, chemical and biological dynamics in water distribution systems so that the current demand for generating a trained work force and maintaining our aged water infrastructure can be met.

Under the support of a NSF TUES grant, the project team aims to address the current lack of integrated water distribution system education by providing laboratory modules and kits coupled with a computational modeling tool for hydraulics and water quality simulation in water distribution systems. Seven function-adaptable kits and modules (4 basic and 3 integrated modules) have been developed and tested. Using modules and lab exercises, students have had the opportunity to synthesize and interpret multiple information sources from lab exercise kits and to utilize them in the building and calibrating of water quality simulations.
\end{abstract}

\section{Introduction}

Water distribution systems are designed to provide water in sufficient quantities and acceptable quality to individual households, commercial properties, and industrial clients. Recently, the American Water Works Association compiled statistical data on water distribution systems and reported that there is over 800,000 miles of distribution pipes are buried in the US ${ }^{[1,2]}$. Water distribution systems are complex inter-connected networks where biological and chemical reactions occur during the hydraulic conveyance of water.

Though the water distribution system is a major component in the water infrastructure, there has been a fundamental discrepancy of integrated and interdisciplinary methods to educate civil engineering students. Integration of chemical, biological and hydraulic dynamics are required for field engineers at water utilities and engineering consulting firms to effectively understand, upgrade and design water distribution systems. 
However, current curriculums and texts have not emphasized systematic approaches to educate students in understanding this dynamic system. In many ABET accredited civil or environmental engineering curriculums, water treatment and hydraulics (water resources engineering) courses are taught to undergraduate students with some lab experiments. Water treatment labs focus on monitoring and controlling drinking water quality (ex. jar tests, adsorption, hardness, softening, and chlorine tests), while fluid mechanics courses (ex. fluid mechanics, hydraulics, and water resources engineering) focus on theoretical concepts of fluid dynamics (ex. energy equation, friction loss, fluid in closed conduits, and open channel systems). Increased public health risks due to aged water distribution systems necessitate the maintenance of our aged water infrastructure, which academia has largely neglected the need to fully educate students in understanding the complex behavior of these systems.

Currently, in spite of present dynamics and complexities in water distribution systems, fluid mechanics and hydraulic courses are taught to engineering students (civil, chemical, environmental, and mechanical engineering students) focus only on the physical properties and dynamics of fluids. Consequently, students have difficulties in transferring knowledge from one context to another even within the scope of engineering course work. Educational research has identified that if students are taught in a way that become "context-bound", it is more difficult for students to transfer that knowledge into other context ${ }^{[3]}$. Furthermore, there is also lack of commercially available educational materials that address both the theory and application of water distribution system dynamics ${ }^{[4-11]}$.

This study endeavors to address current needs in educating undergraduate students in water distribution systems providing seven function adaptable water distribution system analysis lab (WDSAL) modules and kits. Developed WDSAL modules and kits from this project will employ an integrated approach to address biological, chemical, and hydraulic dynamics in water distribution systems. The outcomes of this project will provide hands-on laboratory and modeling experiences related to fluid mechanics, hydraulics, water chemistry and microbiology to undergraduate students providing interdisciplinary lab experiences related to real life engineering projects. Also, students will have opportunities to generate and interpret multiple information sources from lab exercises with the kits and to utilize them in model building and calibration of real water distribution systems.

\section{Laboratory Module and Kit Development}

During the first year project period, four basic modules and kits were designed and developed at the PI's home institute. These four basic lab modules and their specific objectives are shown in Table 1. Considering the specific objectives of each lab, modules and kits were constructed and pretested before classroom implementation with participating graduate students. Based on pretests, potential problems (e.g. total lab time, data reproducibility, and workability) were identified and addressed to develop laboratory manuals as well as laboratory kits.

Table 1 Basic Modules and Their Objectives

* BIO: Biological dynamics, CHE: Chemical dynamics, HYR: Hydraulic dynamics, and MAM: Mathematical Modeling 


\begin{tabular}{|c|c|c|}
\hline \multicolumn{2}{|c|}{ Modules } & Objectives \\
\hline \multirow{4}{*}{$\begin{array}{l}\frac{1}{0} \\
\frac{0}{3} \\
\sum_{0}^{0} \\
0 \\
0 \\
0 \\
0 \\
0\end{array}$} & $\begin{array}{l}\text { Disinfectant } \\
\text { Decay } \\
\text { Kinetics } \\
\text { (CHE) }\end{array}$ & $\begin{array}{l}\text { Understand why disinfectants are employed in the } \\
\text { distribution system } \\
\text { - Understand how disinfectants react with various } \\
\text { disinfectant consuming materials [ex. Different pipe } \\
\text { materials, Natural Organic Matter (NOM) and biofilm] } \\
\text { - Calculate bulk and wall reaction coefficients }\end{array}$ \\
\hline & $\begin{array}{l}\text { Disinfection } \\
\text { Kinetics } \\
\text { (BIO) }\end{array}$ & $\begin{array}{l}\text { Understand the importance and effectiveness of } \\
\text { disinfectants to control microbial contaminants. } \\
\text { - Understand the influence of structure of bacteria on } \\
\text { disinfection kinetics. } \\
\text { - Understand persistence of biological contaminants }\end{array}$ \\
\hline & $\begin{array}{l}\text { Energy losses in } \\
\text { pipe } \\
\text { (HYR) }\end{array}$ & $\begin{array}{l}\text { Understand mass and energy equation } \\
\text { - Understand major head loss due to pipe friction } \\
\text { - Understand minor head loss due to fittings }\end{array}$ \\
\hline & $\begin{array}{l}\text { Tracer Study } \\
\text { (HYR, CHE) }\end{array}$ & $\begin{array}{l}\text { - Understand transmission of fluid and contaminates in } \\
\text { closed pipe systems } \\
\text { - Understand dispersion and mixing of chemical in } \\
\text { closed pipe systems }\end{array}$ \\
\hline
\end{tabular}

All basic modules were designed to utilize a model distribution system (a simple pipe network system). Therefore, an important part of basic module and kit preparation also included construction of an adaptable model distribution system. This adaptable setup was expected to offer far greater adaptability to simulate different distribution conditions. However, a system composed of flexible tubing based systems with union connectors showed a water leaking problem under pressurized system conditions. As a result, PVC based pipe system components with coupling joints were made as assembly components, which can be used to build various pipe network with different configurations (Figure 1 and 2). Using PVC pipe components provided the additional benefit that each component can be easily dismantled and cleaned after biological and chemical dynamics tests.

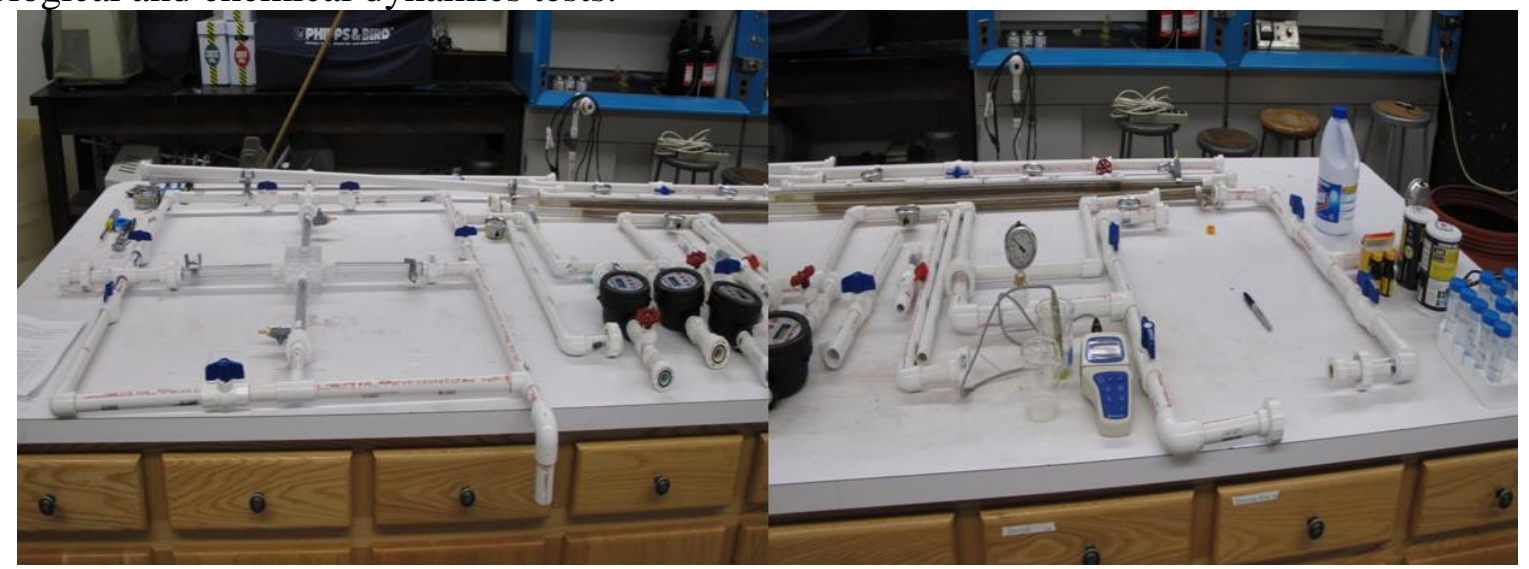

Figure 1. PVC Based Pipe System Components as Assembly Blocks for Lab Exercises 


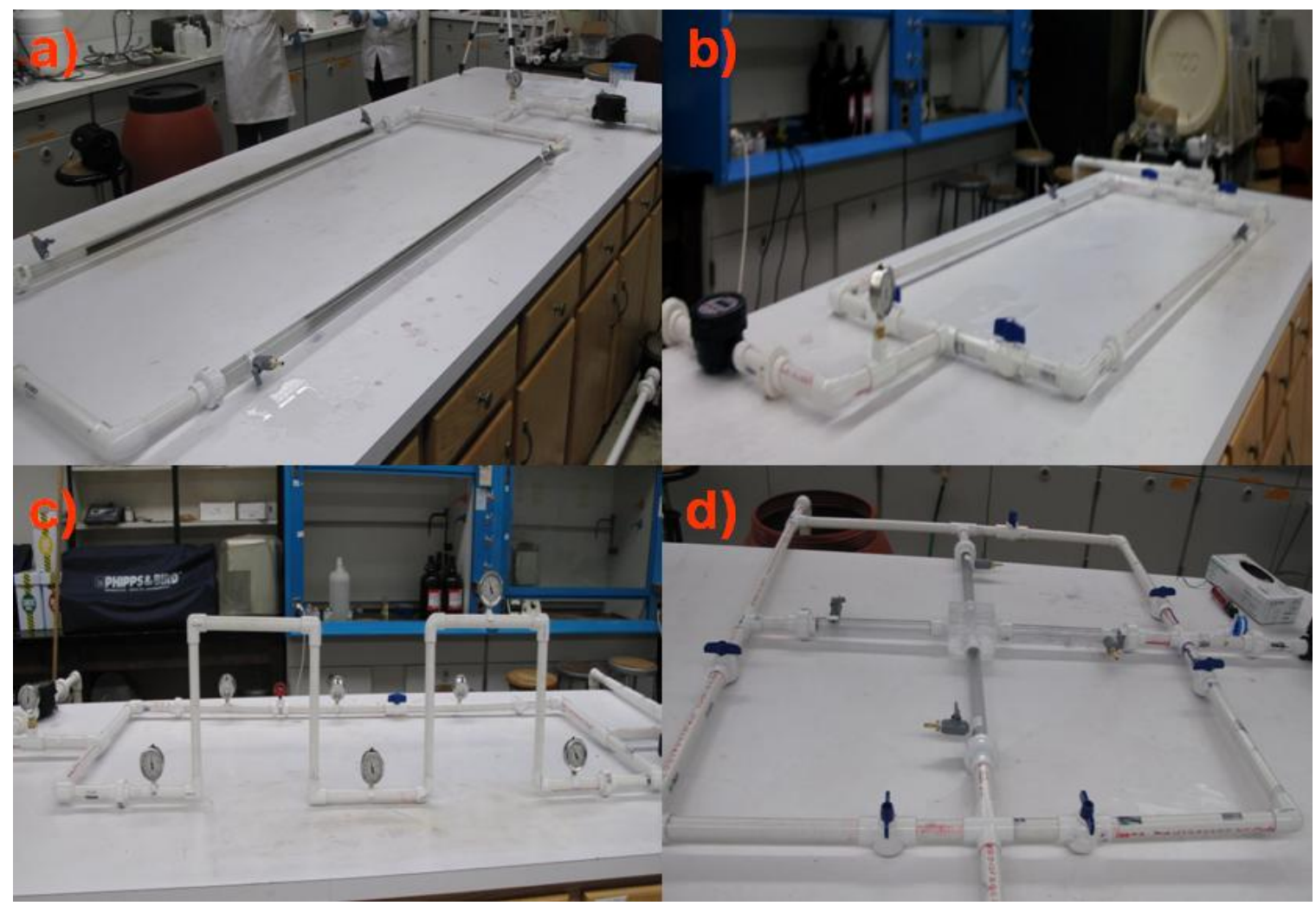

Figure 2. Pipe Network Configuration for Different Basic Lab Modules: a) Disinfectant Decay, b) Disinfectant Kinetic Lab, c) Energy Loss, d) Contaminant Transport (Tracer Study/Mixing)

Using data from the basic modules, integrated modules coupled with mathematical modeling with the EPANET were developed and employed to help students understand the combined impact of chemical, biological, and hydraulic dynamics in the water distribution systems. Table 2 shows integrated modules and their objectives.

In order to increase students' understanding, new course materials were also developed addressing dynamics (physical, chemical, and biological) in water distribution systems before relevant classes for modeling with the EPANET. Relevant lectures were delivered for students to understand the fundamental principles employed by EPANET simulation along with practical in-class exercises. In the previous semester lectures, in-class EPANET simulation exercises were only developed for hydraulics analysis and not the holistic analysis. During this project period, lecture materials as well as step by step guidelines for water quality simulation (e.g. disinfectant decay, contaminant transport, and contaminant disinfection) were prepared using EPANET.

Lab manuals for basic modules and kits have been developed for student use. Developed lab manuals are composed of an introduction/ background, procedure, data sheet, and a question section for data analysis to guide the students. Many lab manuals also include an appendix for step by step procedures with figures. Lab manuals for instructors were also prepared for the disinfection kinetic lab (for spore and bacteria suspension preparation protocols), the disinfectant decay lab (for chlorine and natural organic matter solution preparation), and contaminant mixing 
lab (for solution preparation and conductivity analysis procedures). Also, for instructors, answer keys with EXCEL spread sheets were provided for exercise questions.

Table 2 Integrated Modules and Their Objectives

* BIO: Biological dynamics, CHE: Chemical dynamics, HYR: Hydraulic dynamics, and MAM: Mathematical Modeling

\begin{tabular}{|c|c|c|}
\hline \multicolumn{2}{|c|}{ Modules } & Objectives \\
\hline \multirow{3}{*}{ 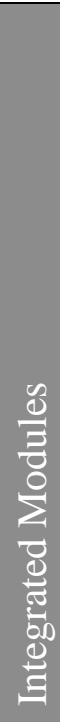 } & $\begin{array}{l}\text { Water Quality } \\
\text { (Disinfectant Decay in } \\
\text { Water Distribution } \\
\text { System) Monitoring \& } \\
\text { Simulation } \\
\text { (CHE-HYR-MAM) }\end{array}$ & $\begin{array}{l}\text { - Understand the influence of water age, NOM and } \\
\text { pipe material on disinfectant decay and } \\
\text { consumption in distribution systems } \\
\text { - Understand bulk and pipe wall reaction } \\
\text { - Simulate disinfectant concentration changes in a } \\
\text { model distribution system with mathematical } \\
\text { modeling }\end{array}$ \\
\hline & $\begin{array}{l}\text { Biological Water Quality } \\
\text { Monitoring \& Simulation } \\
\text { (BIO-HYR-MAM) }\end{array}$ & $\begin{array}{l}\text { - Understand the influence of water age on } \\
\text { disinfectant decay and biological stability } \\
\text { - Practice mathematical model calibration and } \\
\text { simulation with experimental data. }\end{array}$ \\
\hline & $\begin{array}{l}\text { Distribution system } \\
\text { decontamination } \\
\text { (BIO-CHM-HYR-MAM) }\end{array}$ & $\begin{array}{l}\text { - Monitor, simulate and explain dynamics of water } \\
\text { distribution system. } \\
\text { - Practice mathematical model calibration with } \\
\text { experimental data. }\end{array}$ \\
\hline
\end{tabular}

Initially the integrated lab modules were planned to be developed for in-class exercises. However, considering conventional class schedules and topics for hydraulics and water resources engineering courses (e.g. open channel flow, pipe flow, hydrology, etc), integrated lab manuals were developed and incorporated into design term projects with the EPANET. EPANET term project information was based on an EPANET assignment created by Dr. Steve Buchburger at the University of Cincinnati, which utilizes one of the example codes from the EPANET software package. With the permission of Dr. Buchberger, the assignment was modified and updated as a design term project where each student applied measured experimental parameters from his or her basic labs to water quality and hydraulics simulation using step by step tutorial guidelines.

\section{First Year Implementation}

During the first year project period, developed basic modules were tested and evaluated via three courses at two institutions (CIVE 3610 "Water Supply and Treatment", CIVE 4610/5610/8900 "Hydrology and Water Resources Engineering”, CEE 333 "Water Resources Engineering”).

\section{\# CIVE 4610/5610 Hydrology and Water Resources Engineering}

This course is cross listed for both undergraduate and graduate students at the University of Toledo. Previously, the CIVE 4610/5610 class did not utilize any laboratory components. Thus, the course was modified to include all basic and integrated lab modules and they were tested and evaluated during the first year project period. There were 17 total students (13 undergraduates and 4 master students) who took the class. After conducting each lab, students were asked to 
submit a group laboratory report which included a summary of results and discussions. Utilizing information obtained from basic lab exercises, integrated lab modules were incorporated into problem based water distribution system analysis questions and a design term project with EPANET simulations (contaminant transport/mixing was introduced as a part of lab exercise). During the testing of all modules and kits, student surveys and evaluations were conducted for all developed basic modules and integrated modules (via term project evaluation).

\section{\# CIVE 3610 Water Supply and Treatment}

The disinfectant decay lab module was introduced to the course at the University of Toledo where total 59 students had the opportunity to conduct a lab exercise for monitoring chlorine reactivity and decay with various materials (corroded pipe materials, isolated natural organic matter, and supplementary organic material such as dry leaves). In order to help students understand disinfectant chemistry, lecture material was developed and delivered regarding fundamental disinfection chemistry and reactivity. The disinfection kinetic lab module was also planned to be tested in the course as well. However, due to the high number of registered students and limited laboratory time, the disinfection kinetic module was not introduced in this class.

\section{\# CEE 333 Water Resources Engineering}

CEE 333 is one of the first design courses for civil engineering students at the University of Dayton. The material presented in CEE 333 includes water supply and distribution, rainfall/runoff generation, storm water management, storm sewer design, and sanitary sewer design. The water distribution component of the course utilizes the EPANET simulation model. In this class, there were a total of 36 students that had the opportunity to conduct a disinfectant decay lab and understand chlorine decay kinetics.

\section{Evaluations}

Both student and instructor assessment surveys were prepared for lab modules and kits. The surveys had approximately 10 to 15 questions consisting of a 1-5 point Likert-type scale, which was analyzed using Rasch modeling to convert to an interval scale and correlated to student's learning and improvement of instructors' expertise scores. A detailed analysis and specific evaluation of each component in the modules and kits were completed via detailed student surveys for basic modules and kits. Since integrated modules were incorporated into the design term project, student survey for the term project was conducted for integrated modules. Lab modules and kits were also evaluated with Teaching Assistants' feedback, instructors' feedback, and the course evaluation forms from the participating college of engineering institutions.

\section{Findings and Lesson Learned}

Developed modules and kits were extensively tested via CIVE 4610/5610 at the University of Toledo. Material presented in the course included fluid dynamics, water distribution system design and evaluation, and open channel system design. In order to adapt and test developed lab modules and kits, the course structure was changed to enhance students' understanding on dynamics in water distribution systems in tandem with lab modules. For the modified course schedule, fundamentals of pipe flow were discussed before introducing EPANET and 
corresponding exercises. Then, students performed the lab exercises with the developed lab modules and kits. The final term project (integrated lab modules) was also introduced in advanced to provide sufficient time for students to complete the project. Considering students' lab report preparation time, only one lab module was introduced each week in between regular lecture classes.

Overall, student responses and evaluations to introduced lab modules and kits were positive and participating students showed enthusiasm in lab exercises observing the various parameters that may affect water quality in full scale drinking water distribution systems. However, not all students appreciated additional laboratory exercises which required group laboratory report preparations. Figure 3 shows the exemplary student survey results (selected two questions) of basic and integrated lab modules for the CIVE 4610/5610 ( $\mathrm{n}=17)$.

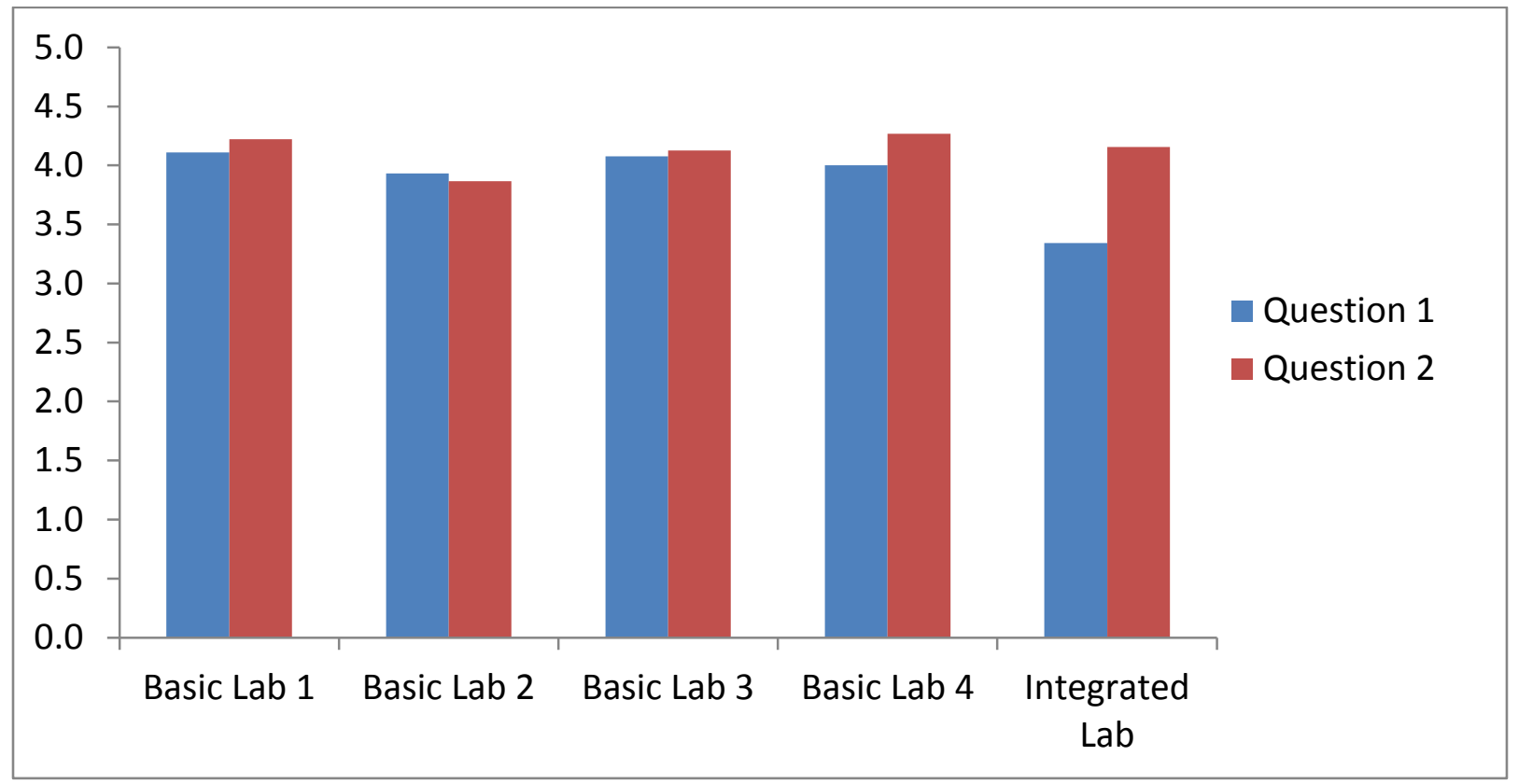

Figure 3. Exemplary Student Survey Results of Basic and Integrated Lab Modules for the CIVE 4610/5610 $(n=17)$

* Question 1) After conducting this lab, my understanding on water distribution systems increased than before.

* Question 2) The lab experience broadened my understanding of real world problem and concerns faced by engineers.

While introducing lab modules and kits, the PI observed that organizing the course schedule is very important for maintaining students' attention as well as increasing students' understanding without overburdening students. Based on the first year implementation experience, two issues were brought up related to the course schedule arrangement.

First, when basic lab modules and kits were introduced after completing all relevant lectures, students were not fond of lab report preparation along with other class assignments for new course information (e.g. open channel flow and system design). The basic lab modules need to be spread out carefully during regular classes for pipe flow systems in order to more efficiently convey the material. Second, lab exercises with basic lab modules and kits overlapping with 
other lecture materials decreased students' attention and focus to new lecture material. Additionally, with the term project for water distribution system analysis and design, some students told the PI that they felt that they kept working with water distribution system analysis until the end of semester, even though the class lectures continued to cover new information in other branches of water resources relevant to the Exams. In order to maintain students' interests as well as enhance their understanding for course information, the PI plans to restructure the course schedule by introducing open channel flow information first followed by the fundamentals for pipe flow systems with lab and modeling exercises.

In summary, the preliminary data obtained from the first year project confirms that the developed lab modules and kits could increase students' understanding of water distribution networks by providing systematic information and concepts as well as their interaction associated with biological, chemical, and hydraulic dynamics in water distribution systems. Survey information also showed that lab modules and kits also could help students to understand real world problems by adapting and implementing problem based learning modules in the context of real-life application.

\section{Acknowledgements}

This research was supported by the National Science Foundation (Award Number: TUES1044823).

\section{Bibliography}

1. EPA(Environmental Protection Agency), Drinking water infrastructure needs Survey and Assessment Fourth Report to Congress EPA/600/R-09/048, 2009.

2. ASCE (American Society of Civil Engineers) Report card for American's infrastructure http://www.asce.org/reportcard/2005/page.cfm?id=24\#policy

3. NAE (National Academy of Engineering), How People Learn: Brain, Mind, Experience, and School, Bransford, J., Brown, A. L., Cocking, R. R. editors, National Academy Press, Washington, 1999.

4. Qasim, S. R., Motley, E. M., Zhu, G. Water Works Engineering: Planning, Design \& Operation., Prentice Hall, New Jersey, 2000.

5. Reynolds, T.D., Richards, P. A., Unit Operations and Processes in Environmental Engineering, $2^{\text {nd }}$ ed, PWS

Publishing, Boston, 1996.

6. Hammer, M. and Hammer, M. Jr., Water and Wastewater Technology, $6^{\text {th }}$ ed, Prentice Hall, New Jersey, 2007.

7. Davis, M., Water and Wastewater Engineering, McGraw Hill, New York, 2009.

8. MWH, Water Treatment; Principles and Design, 2nd ed., John Wiley \& Sons, New York, 2005.

9. AWWA (American Water Works Association), Water Quality \& Treatment, 5th ed., McGraw Hill, New York, 1999.

10. Chin, D. A., Water Resources Engineering, 2nd ed.; Pearson Prentice Hall: Upper Saddle River, N.J., 2006.

11. Mays, L. W. Water Resources Engineering, John Wiley \& Sons, New York, 2005. 